\title{
Evaluating transport in the WRF model along the California coast
}

\author{
C. E. Yver ${ }^{1}$, H. D. Graven ${ }^{1}$, D. D. Lucas ${ }^{2}$, P. J. Cameron-Smith ${ }^{2}$, R. F. Keeling ${ }^{1}$, and R. F. Weiss ${ }^{1}$ \\ ${ }^{1}$ Scripps Institution of Oceanography, UC San Diego, 9500 Gilman Drive, La Jolla, CA 92093-0244, USA \\ ${ }^{2}$ Atmospheric, Earth, and Energy Division; Lawrence Livermore National Laboratory, 7000 East Avenue, Livermore, \\ CA94550, USA
}

Correspondence to: C. Yver (cyver@ucsd.edu)

Received: 18 June 2012 - Published in Atmos. Chem. Phys. Discuss.: 10 July 2012

Revised: 22 December 2012 - Accepted: 8 February 2013 - Published: 19 February 2013

\begin{abstract}
This paper presents a step in the development of a top-down method to complement the bottom-up inventories of halocarbon emissions in California using high frequency observations, forward simulations and inverse methods. The Scripps Institution of Oceanography high-frequency atmospheric halocarbons measurement sites are located along the California coast and therefore the evaluation of transport in the chosen Weather Research Forecast (WRF) model at these sites is crucial for inverse modeling. The performance of the transport model has been investigated by comparing the wind direction and speed and temperature at four locations using aircraft weather reports as well at all METAR weather stations in our domain for hourly variations. Different planetary boundary layer (PBL) schemes, horizontal resolutions (achieved through nesting) and two meteorological datasets have been tested. Finally, simulated concentration of an inert tracer has been briefly investigated. All the PBL schemes present similar results that generally agree with observations, except in summer when the model sea breeze is too strong. At the coarse $12 \mathrm{~km}$ resolution, using ERA-interim (ECMWF Re-Analysis) as initial and boundary conditions leads to improvements compared to using the North American Model (NAM) dataset. Adding higher resolution nests also improves the match with the observations. However, no further improvement is observed from increasing the nest resolution from $4 \mathrm{~km}$ to $0.8 \mathrm{~km}$. Once optimized, the model is able to reproduce tracer measurements during typical winter California large-scale events (Santa Ana). Furthermore, with the WRF/CHEM chemistry module and the European Database for Global Atmospheric Research (EDGAR) version 4.1 emissions for HFC-134a, we find that using a simple emission scaling factor is not sufficient to infer emissions, which highlights the need for more complex inversions.
\end{abstract}

\section{Introduction}

In the past decades, the implementation of measures within the United States and other countries to monitor the emissions of greenhouse gases (GHGs) progressed rapidly. This progress is due to the scientific consensus that GHG emissions are causing climate change (IPCC, 2007) and has led to the formation of several regional initiatives for reducing emissions, including California's pioneering Global Warming Solutions Act of 2006 (AB-32) administered by the California Air Resources Board (CARB). Improving the accuracy in GHG emissions quantification has become a critical need in testing the success of environmental policies to achieve the targeted overall reductions (Nisbet and Weiss, 2010). Emissions are typically estimated through "bottomup" methods, using economic reporting, emission factors and a conversion algorithm. "Top-down" methods are independent validation techniques that use modeling of atmospheric transport combined with measurements of the tracer of interest and an inversion algorithm to infer emissions. The two methods are subject to different kinds of uncertainties. In the top-down approach, the uncertainties come from the transport model and the precision and sensitivity of the observations to the emissions in the region of interest.

The Scripps Institution of Oceanography (SIO) has been conducting high-frequency atmospheric measurements of halocarbons, including hydrofluorocarbons (HFC), at two coastal sites in California for many years: La Jolla $\left(32.86^{\circ} \mathrm{N}\right.$, $\left.117.25^{\circ} \mathrm{W}\right)$ in the south and Trinidad Head $\left(41.05^{\circ} \mathrm{N}\right.$, $124.15^{\circ} \mathrm{W}$ ) in the north. These measurements are carried out under the auspices of the NASA-sponsored Advanced Global Atmospheric Gases Experiment (AGAGE) (Prinn et al., 2000). Among numerous other gases, HFC-134a is 
measured at both stations. HFC-134a is a refrigerant used widely in automobile air conditioners as a replacement for CFC-12, a stratospheric ozone depleting substance banned by the Montreal Protocol. HFC-134a is a potent GHG with a global warming potential (GWP) of 1300 (over $100 \mathrm{yr}$ ) and a lifetime of $14 \mathrm{yr}$. It is regulated by the Kyoto Protocol and by other GHG legislation, including California's AB-32.

The AGAGE measurements can be used in a top-down approach to deduce emissions in combination with a Bayesian inversion algorithm and simulated mixing ratios. It is crucial to model the winds and other meteorological parameters as accurately as possible to minimize atmospheric transport errors. Modeling these parameters within the lowest few hundred meters above the Earth's surface is still challenging, especially when complex topography is involved. At coastal sites, such as the two SIO stations, the sea breeze phenomenon adds complexity to the atmospheric motions. In the case of California, both the topography and the air-sea interactions lead to complex air flow. Fortunately, important meteorological parameters (wind direction, wind speed and temperature) are regularly measured and available to evaluate model simulations at coastal locations, for example through the Aircraft Communications Addressing and Reporting System (ACARS), which allows aircraft to transmit weather report during take-off and landing above airports.

In this paper we investigate the transport characteristics in the Weather Research Forecast (WRF) model as part of a broader goal of estimating Californian HFC emissions accurately. This work is in the line of recent papers which have explored transport in California (Fast et al., 2011; Angevine et al., 2012). We first describe the WRF configuration, options, and schemes tested. Then, we briefly detail the data used for comparison. Finally, we investigate the results of the simulations and the synoptic and monthly scales and evaluate the model performance, as well as the impact of the modifications on the modeling of the effectively inert tracer HFC134a.

\section{Description of the WRF model and its inputs for this study}

\subsection{WRF basic configuration}

The regional meteorological model used in this study is the WRF Model with Advanced Research WRF (ARW) dynamic core version 3.3.1 (Skamarock and Klemp, 2008). WRF is a limited-area, non-hydrostatic, terrain-following eta-coordinate mesoscale modeling system. In this study, the Lambert conformal conic projection is used as the model horizontal coordinates. In the vertical, there are twenty eight levels. The coarse domain of our study is a $12 \mathrm{~km}$ resolution grid covering California (center coordinates are $38^{\circ} \mathrm{N}$, $120^{\circ} \mathrm{W}$ ) and a portion of surrounding states, Mexico, and the Eastern Pacific Ocean as shown in Fig. 1. The grid is

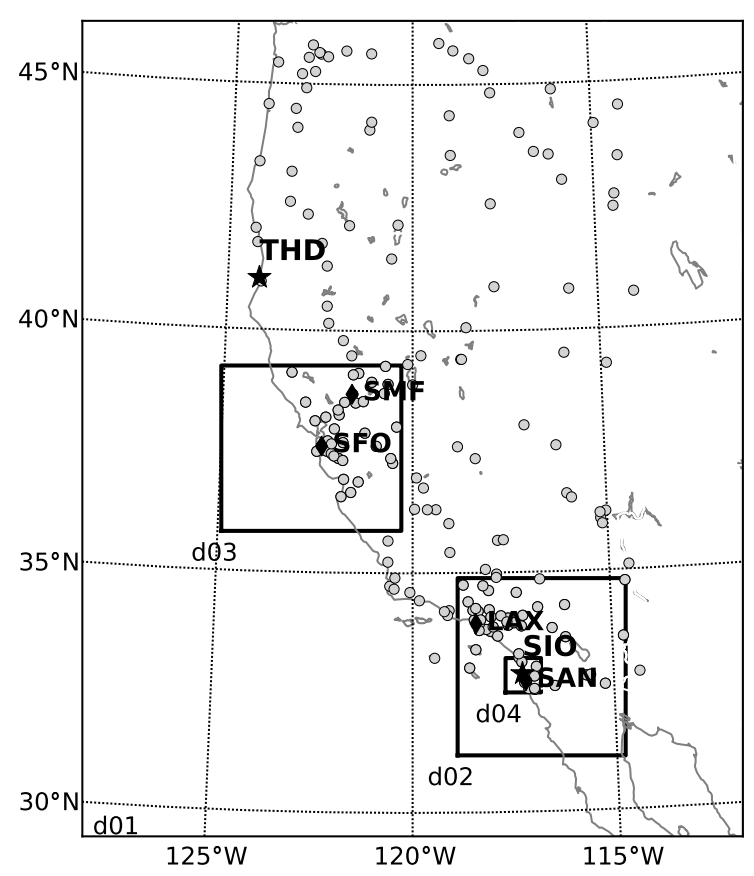

Fig. 1. WRF domain with the coarse $(12 \mathrm{~km})$ domain (d01) and three higher resolution nests ( $\mathrm{d} 02$ and $\mathrm{d} 03$ at $4 \mathrm{~km}$ resolution and d04 at $0.8 \mathrm{~km}$ resolution). Airports (SAN: San Diego, LAX: Los Angeles, SFO: San Francisco, SMF: Sacramento) are plotted as black diamonds. The measurement sites of La Jolla (SIO) and Trinidad Head (THD) are indicated by a black star. Location of the METAR surface weather stations is shown with a grey dot.

composed of 129 cells covering about 20 degrees in longitude $(1500 \mathrm{~km})$ and of 159 cells covering about 15 degrees in latitude $(1900 \mathrm{~km})$. The chosen temporal resolution of the output is two hours to match the temporal resolution of the HFC measurements at La Jolla and Trinidad Head.

One useful capability of WRF is its flexibility in choosing different dynamical and physical schemes. In our study, several physics parameterizations have been changed from the default parameterizations to better represent physical and dynamical processes along the California coast. Diffusion is of the second order following the 2-D Smagorinsky scheme (Smagorinsky, 1963). The short and long wave radiation schemes are the new Rapid Radiative Transfer Model for Global climate models (RRTMG) schemes with a radiation time-step of 12 minutes (Mlawer et al., 1997). We have chosen the NOAH land surface model (Chen and Dudhia, 2001). Considering the size of our grid, we use the Grell-3-D cumulus scheme (Grell and Dévényi, 2002). For the microphysics, we use the WSM 3-class scheme (Hong et al., 2004). Finally, to better represent coastal phenomena, the sea surface temperature (SST) update option is activated. These schemes remain constant throughout the testing of different planetary boundary layer (PBL) schemes, nesting grids and initial and boundary conditions. 


\subsection{Planetary Boundary Layer schemes}

The PBL is the part of the atmosphere closest to the ground and is strongly affected by diurnal heat, moisture and momentum transfer to and from the surface. The PBL height undergoes a distinct diurnal cycle over land. At night, with decreasing temperature, the top of the PBL is lower than during the day. The PBL develops in the morning and usually reaches its maximum extent in mid-afternoon. Over the ocean, the PBL diurnal cycle is weaker, nonexistent or reversed (Bretherton et al., 2004). Modeling the diurnal cycle of the PBL requires accurate simulations of sub-daily fluxes of heat, moisture and momentum.

WRF offers the choice between ten different planetary boundary layer schemes. Turbulent fluxes of heat, momentum and constituents such as moisture are not resolved at the time steps and grid size used and therefore are parameterized through these schemes. There are different parameterizations depending on whether the fluxes are estimated only from local variables and/or their gradients (local closure, Holt and Raman (1988); Hu et al. (2010)) or if non local fluxes are added (non-local closure). These non-local terms can then be either parameterized (Noh et al., 2003) or treated explicitly (Pleim, 2007a,b; Pleim and Chang, 1992). Moreover, the local parameterization can be first or oneand-a-half (Total Kinetic Energy, TKE) order which will have an impact mainly on the turbulent structure (Holt and Raman, 1988). Here, a one-month simulation over January 2009 was run for eight of these schemes. These parameterizations are detailed in Hong et al. (2006) (YSU), Janjic (2002) (MYJ), Sukoriansky et al. (2005) (QNSE), Nakanishi and Niino (2006) (MYNN2), Pleim and Chang (1992) (ACM2), Bougeault and Lacarrère (1989) (BouLac), Park and Bretherton (2009) (UW) and Angevine et al. (2010) (TEMF). Among the eight PBL schemes that will be evaluated in this study, the MYJ, Boulac, QNSE, MYNN2, UW and TEMF schemes are one-and-a-half order schemes, while the YSU and ACM2 schemes are first order schemes. Moreover, the YSU, ACM2 and TEMF are non-local closure models while the rest are local closure models. Several studies have looked at the performances of one or several of these PBL schemes. To our knowledge, there is no study comparing all of the above schemes in a single paper. The main conclusions of these previous studies are that no scheme performs better than the others under all circumstances ( $\mathrm{Hu}$ et al., 2010; Gibbs et al., 2011; Shin and Hong, 2011). Usually, each scheme will have strengths and weaknesses.

\subsection{Different horizontal resolutions through nesting}

Nesting consists of defining another domain within the main domain, with a higher spatial resolution around regions of interest. Typically, nesting increases the resolution in a limited area around the measurement sites, which can provide a better simulation of the winds as well as other parameters such as temperature or PBL height near the measurement sites. The WRF model has one- and two-way nesting capabilities and can accommodate multiple embedded nests. We use oneway nesting in this study in order to isolate differences in the different resolution nests. The one-way nesting is performed as follows. First, the parent (outer) domain is integrated for one time step. Next, its values are interpolated and communicated to the nest boundaries. The nest (inner) domain is then integrated for the small-grid time interval to reach the parent domain's time level (Skamarock and Klemp, 2008). In our case, we have run the model with two levels of embedded nests around San Diego/Los Angeles area and a single nest around the San Francisco Bay area, as shown in Fig. 1. The coarse domain (d01) is the $12 \mathrm{~km}$ resolution grid. The medium domains ( $\mathrm{d} 02$ and $\mathrm{d} 03$ ) have a $4 \mathrm{~km}$ resolution with a $100 \times 100$ grid size. The finer domain (d04) has a $0.8 \mathrm{~km}$ resolution with a 101x101 grid size.

\subsection{Initial and lateral boundary conditions}

Meteorological datasets provide initial conditions and lateral boundary conditions for limited-area models. The WRF preprocessing system interpolates the data onto the model grid at all vertical levels for the initialization. It also calculates the values at the coarse domain lateral boundaries for each specified time interval (typically $6 \mathrm{~h}$ ).

We compare two different meteorological datasets. The first meteorological dataset is a forecast product and comes from the National Centers for Environmental Prediction (NCEP) North American Model (NAM) with a $12 \mathrm{~km}$ and $6 \mathrm{~h}$ resolution (http://nomads.ncdc.noaa.gov/data/namanl/). To represent the coastal wind patterns more accurately, we use the sea surface temperature (SST) dataset RTG_SST_HR data (Real-Time Global SST) from NCEP at a 0.083 degree resolution $(\approx 9 \mathrm{~km})$ and 24 hour frequency (ftp:// polar.ncep.noaa.gov/pub/history/sst/ophi/). The second meteorological dataset comes from the European Center for Medium Range Weather Forecasts (ECMWF) and is the ECMWF Re-Analysis (ERA-interim) (with observation assimilation) with $\mathrm{a} \approx 80 \mathrm{~km}$ and $6 \mathrm{~h}$ resolution combined with the Global Ocean Data Assimilation Experiment (GODAE) high-resolution $(\approx 9 \mathrm{~km})$ SST data set from the US Navy updated every $6 \mathrm{~h}$ (http://www.usgodae.org/ftp/ outgoing/fnmoc/models/ghrsst/). In the case of NAM, the provided data are forecasts, while for ERA-interim, the provided data are reanalyses, that is to say, forecasts corrected using observations a posteriori and using a consistent analysis system over the whole period. ERA-interim should then provide data with better accuracy but lower resolution.

\subsection{Different sets of simulations}

We have carried out four different sets of simulations (see Table 1). In the first set, we have run WRF without nesting with the eight different PBL schemes for the January and August 
2009 one-month periods using the NAM initial and lateral boundary conditions. In the second set, we have compared the two initial and lateral boundary condition datasets (NAM versus ERA-Interim) using simulations covering the whole year 2009 with the MYNN2 PBL scheme. In the third set, we have tested the nesting option in the simulations with the MYNN2 PBL scheme and ERA-interim. As the nested run is computationally intensive, the simulations were conducted for only four months: January, April, July and October 2009. Two nesting configurations have been tested. The first uses $4 \mathrm{~km}$ resolution nests around San Francisco, San Diego and Los Angeles, and one $0.8 \mathrm{~km}$ resolution nest around San Diego. This version has been run for January and July. Then, we have run the simulations without the $0.8 \mathrm{~km}$ resolution nest for April and October. Finally, looking for improvement in the transport of an inert tracer, we used the WRF chemistry module (WRF-CHEM) and changed some options. These different combinations of simulations are summarized in Table 1 .

\section{Observations}

\subsection{ACARS vertical profile data}

To evaluate the vertical transport characteristics of the model simulations, we use the ACARS data provided by aircraft during take-off and landing available on the NOAA website (details at http://madis.noaa.gov/madis_acars.html). As the focus is on coastal sites, we have mainly selected coastal stations. However, we also chose one inland station (Sacramento) to assess the model further inland. The stations are airports at San Diego (SAN), Los Angeles (LAX), San Francisco (SFO) and Sacramento (SMF). The location of each station is given in Table 2 and Fig. 1. The available data are temperature, wind speed and direction measured for 200 vertical levels from the ground to $13 \mathrm{~km}$. In this work, we limit our study to the lowest $4 \mathrm{~km}$. It is important to keep in mind that this profiles are slant profiles that could lead to representation errors over complex terrain. At the model coarse and medium resolution, 12 and $4 \mathrm{~km}$, these errors should be small, however, for the smaller grid, over San Francisco in particular, this error could be non-negligible. For the vertical analysis, data were aggregated by $50 \mathrm{hPa}$ layers from 600 to $1050 \mathrm{hPa}$ before being averaged on a monthly basis to create a vertical profile. The ACARS data cover every day of the year without interruption and with the same mean number of observations. During the day, from 5AM to 12AM, there is a relatively constant number of observations per hour. Before $5 \mathrm{AM}$, there are little to no observations.

\subsection{METAR weather stations}

To assess the meteorology over the whole domain and estimate the model performance at the surface, we use the METAR surface weather stations located in our domain west of $114^{\circ} \mathrm{W}$ and available on the NOAA website (details at http://madis.noaa.gov/madis_sfc.html). As for ACARS, we focus on wind direction, wind speed and temperature. The data are averaged in two hour bins to be compared to the model outputs. For the domain d01, 183 stations are available over 2009. For d02 and d03, 50 and 36 respectively, are available. For all domains, data from the surface stations corresponding to the ACARS chosen airports are available. However, it is notable than at SAN, the surface station has been moved by about one kilometer west between April and July 2009.

\subsection{SIO HFC-134a measurements}

We focus here on the HFC-134a measurements from La Jolla (code: SIO, $32.86^{\circ} \mathrm{N}, 117.25^{\circ} \mathrm{W}, 14 \mathrm{~m}$ a.s.l.). There, a cryogenic preconcentration gas chromatograph-mass spectrometer (GC-MS) system called "Medusa" measures 38 anthropogenic and natural trace gases down to the sub-partsper-trillion concentration range every two hours, including HFC-134a (Miller et al., 2008). This station is located north west of Downtown San Diego and receives air masses from the San Diego area, as well as from the Los Angeles area and other coastal regions further north. Mixing ratios elevated above background are regularly observed. The background is calculated using filtered clean air data from Trinidad Head on a monthly basis (http://agage.eas.gatech. edu/data_archive/agage/gc-ms-medusa/monthly/). We have selected HFC-134a due to its good temporal coverage by the observations during the chosen periods and the availability of emission inventories from the European Database for Global Atmospheric Research (EDGAR) and CARB.

\subsection{HFC-134a emissions}

The HFC-134a emissions that are used in the simulations are the 2005 constant-in-time emissions from the EDGAR inventory version 4.1 (Olivier et al., 1996), available at http: //edgar.jrc.ec.europa.eu/. For this study, we used the HFC$134 \mathrm{a}$ emission map at $0.1 \mathrm{x} 0.1$ degree resolution and interpolated it onto the different domain grids $(12,4$ and $0.8 \mathrm{~km}$ resolution). We scaled the total emission (11.2 million tonnes of $\mathrm{CO}_{2}$ equivalent) by the fractional difference in emissions reported for the whole state of California by CARB between 2005 and 2009, the year we examine in this study. According to the CARB inventory, in California, HFC-134a emissions in 2009 were lower than 2005 by $6 \%$ (8.036 and 8.553 million tonnes of $\mathrm{CO}_{2}$ equivalent respectively, see CARB inventory at http://www.arb.ca.gov/cc/inventory/data/data.htm). 
Table 1. Simulations. For each simulation, the first letter and number refer to the PBL scheme, the second letter refers to the initial and lateral boundary condition datasets ( $\mathrm{N}$ for NAM and $\mathrm{E}$ for ERA-interim). The last 2 numbers are for the grid resolution (12 for $12 \mathrm{~km}, 04$ for $4 \mathrm{~km}$ and 08 for $0.8 \mathrm{~km}$ ). The small letters $\mathrm{b}$ and $\mathrm{c}$ indicate respectively a longer simulation and a simulation with chemistry added in comparison to the code without the letter. For each simulation, the PBL scheme, the initial and lateral boundary condition datasets with their spatial resolution, the period of the simulation as well as additional comments are detailed.

\begin{tabular}{|c|c|c|c|c|c|}
\hline Name & PBL scheme & Meteorological data & Grid res $(\mathrm{km})$ & Period & Other \\
\hline $\mathrm{P} 1 \mathrm{~N} 12$ & YSU & NAM + RTG SST & 12 & Jan \& Aug 09 & 1st order, non-local closure \\
\hline $\mathrm{P} 2 \mathrm{~N} 12$ & MYJ & NAM + RTG SST & 12 & Jan \& Aug 09 & 1.5 st order, local closure \\
\hline P3N12 & QNSE & NAM + RTG SST & 12 & Jan \& Aug 09 & $1.5 \mathrm{st}$ order,local closure \\
\hline $\mathrm{P} 4 \mathrm{~N} 12$ & MYNN2 & NAM + RTG SST & 12 & Jan \& Aug 09 & 1.5 st order, local closure \\
\hline P5N12 & ACM2 & NAM + RTG SST & 12 & Jan \& Aug 09 & 1st order, non-local closure \\
\hline P6N12 & BouLac & NAM + RTG SST & 12 & Jan \& Aug 09 & 1.5 st order, local closure \\
\hline P7N12 & UW & NAM + RTG SST & 12 & Jan \& Aug 09 & $1.5 \mathrm{st}$ order, local closure \\
\hline P8N12 & TEMF & NAM + RTG SST & 12 & Jan \& Aug 09 & $1.5 \mathrm{st}$ order, non-local closure \\
\hline $\mathrm{P} 4 \mathrm{~N} 12 \mathrm{~b}$ & MYNN2 & NAM + RTG SST & 12 & 2009 & NAM 12 km, SST 9km \\
\hline P4E12 & MYNN2 & ERA-interim + GODAE SST & 12 & 2009 & ERA-interim $80 \mathrm{~km}, \mathrm{SST} 9 \mathrm{~km}$ \\
\hline P4E04 & MYNN2 & ERA-interim + GODAE SST & 4 & Jan, Apr, Jul \& Oct 09 & - \\
\hline P4E08 & MYNN2 & ERA-interim + GODAE SST & 0.8 & Jan \& Jul 09 & - \\
\hline $\mathrm{P} 4 \mathrm{E} 12 \mathrm{c}$ & MYNN2 & ERA-interim + GODAE SST & 12 & Dec 09 & CHEM \\
\hline
\end{tabular}

Table 2. Airport locations.

\begin{tabular}{ccccc}
\hline Name & Code & $\begin{array}{c}\text { Latitude } \\
\left({ }^{\circ} \mathrm{N}\right)\end{array}$ & $\begin{array}{c}\text { Longitude } \\
\left({ }^{\circ} \mathrm{E}\right)\end{array}$ & $\begin{array}{c}\text { Altitude } \\
(\mathrm{m} \text { a.s.1. })\end{array}$ \\
\hline San Diego & SAN & 32.73 & -117.19 & 5 \\
Los Angeles & LAX & 33.94 & -118.41 & 38 \\
San Francisco & SFO & 37.62 & -122.38 & 4 \\
Sacramento & SMF & 38.70 & -121.60 & 8 \\
\hline
\end{tabular}

\section{Results}

\subsection{Simulations with eight PBL schemes}

Accurate simulation of the time evolution of the PBL height is crucial to properly simulate the vertical mixing and ventilation of trace gases emitted at the surface. In Fig. 2, the average diurnal cycles of the simulated PBL heights are plotted at SAN in January and August 2009. For this figure, and all the others presenting a diurnal cycle, Pacific Standard Time (UTC-8) is used. On the left, the heights have been calculated using the Richardson bulk number method, while on the right the heights come directly from WRF. For both figures, the schemes simulate a higher PBL height during the day than during the night. However, the PBL height calculated by the individual PBL schemes can differ from the PBL height calculated by the bulk Richardson number, especially for P3N12 (QNSE) and P8N12 (TEMF). If we consider only the WRF diagnostic, that are not all calculated with the same method, it seems that the schemes produce very different PBL cycles and therefore, we would expect a strong influence of these schemes onto the winds and temperature. However, using the
Richardson bulk number method for all schemes shows the PBL schemes are much more similar to each other, especially during the night.

There are not many PBL height measurements available over California. We focus therefore on the effect of the PBL schemes on easily measurable quantities such as temperature, wind speed and wind direction. In Fig. 3, the surface temperature (at $2 \mathrm{~m}$ ), wind direction and wind speed (at $10 \mathrm{~m}$ ) median diurnal cycles are plotted for the San Diego airport in January and August 2009. For all the plots showing diurnal cycles and vertical profiles, the upper and lower quartiles of the concatenated simulation results are plotted except when one simulation presents a strong difference with the other simulations or if the clarity of the plot is not affected. In this case, the interesting simulation quartiles are plotted as well. For the wind direction, wind direction above $180^{\circ}$ indicates winds from the west and wind direction below $180^{\circ}$ winds from the east. Northern winds blow at $180^{\circ}$ and southern winds at 0 or $360^{\circ}$.

All the schemes present similar variation of the median during the day for all parameters. No scheme's median matches the observations better than the others in a consistent way. Moreover, temperature and wind speed are in good agreement with the observations for all of the schemes. In January, the simulated wind direction follows the same cycle as the observations but with winds coming from the southeast instead of south during the night. In August, the land breeze is present in the observations, but not in the simulations except in P8N12 for some of the days, but not the majority as only the lower quartile and not the median reflects the sea breeze. For the other simulations, the simulated winds come only from the west, south-west. Errors in the nighttime wind 
SAN

January
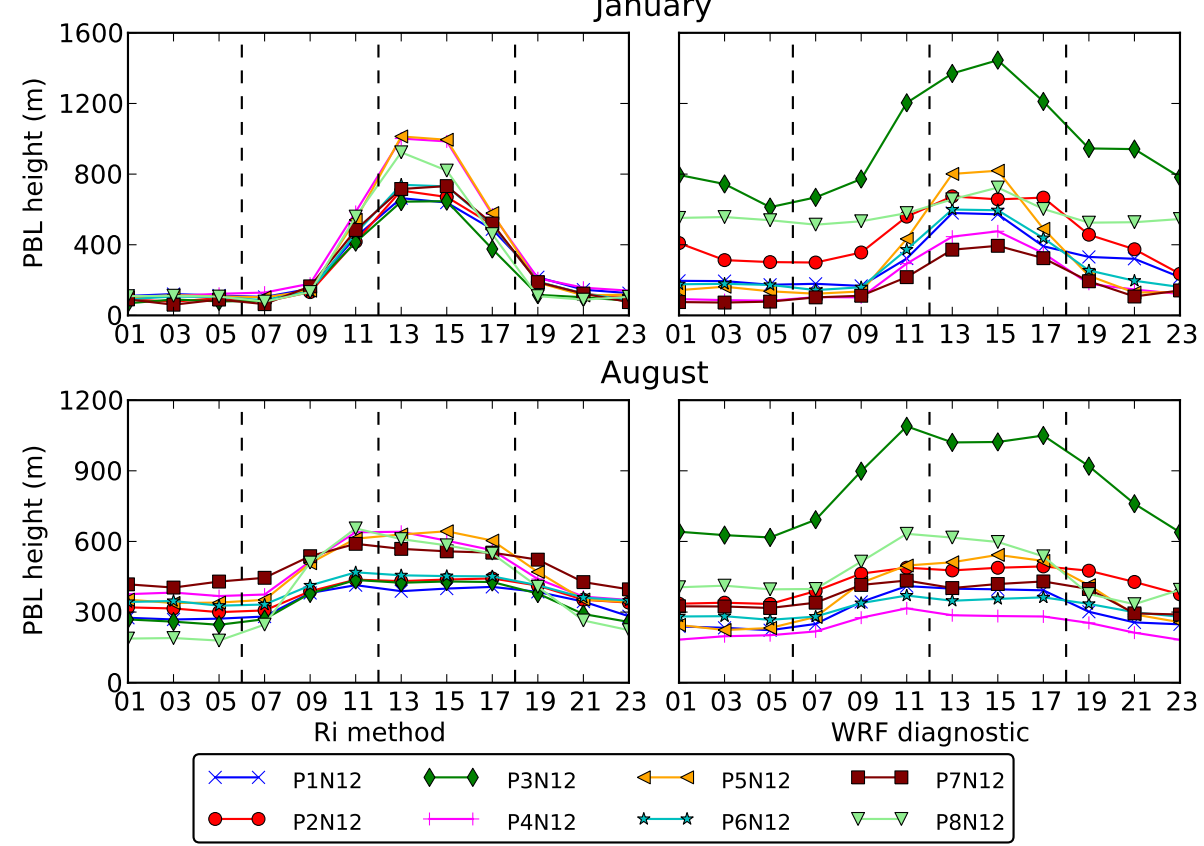

Fig. 2. Diurnal cycle of the simulated PBL heights for the eight PBL schemes at San Diego airport for January and August 2009 (local time) using medians. On the left, the heights as calculated using the Richardson bulk number. On the right, the heights as diagnosed by WRF.

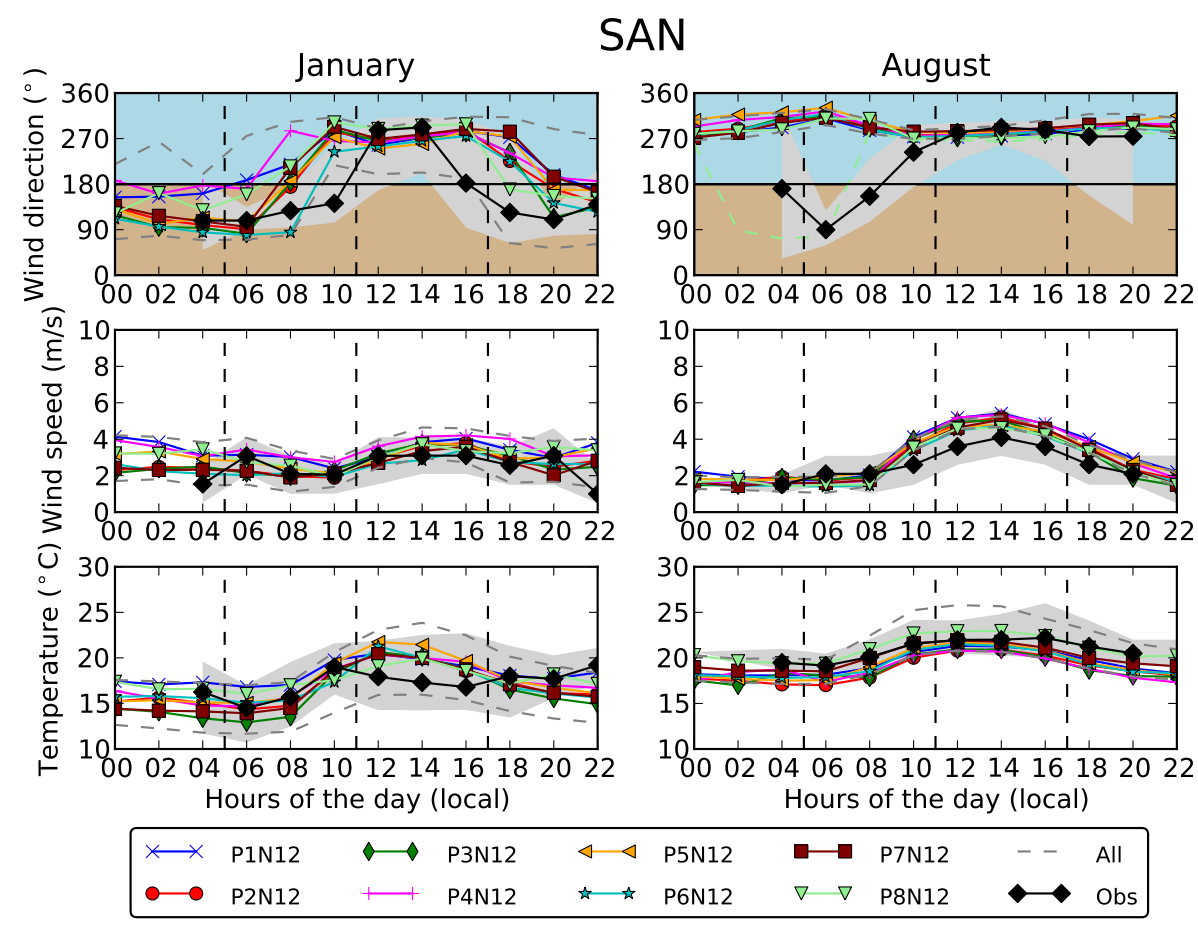

Fig. 3. Diurnal cycle of the surface wind direction, wind speed and temperature for the eight PBL schemes and the observations at San Diego airport in January and August 2009 (local time) using medians. For the wind direction, the blue area represents wind from the west while the tan area is for winds from the east. The grey envelope represents the upper and lower quartiles of the observations. The grey dotted line shows the upper and lower quartiles for all the simulations together. The green dotted line in the august wind direction shows the upper and lower quartile for the P8N12. 


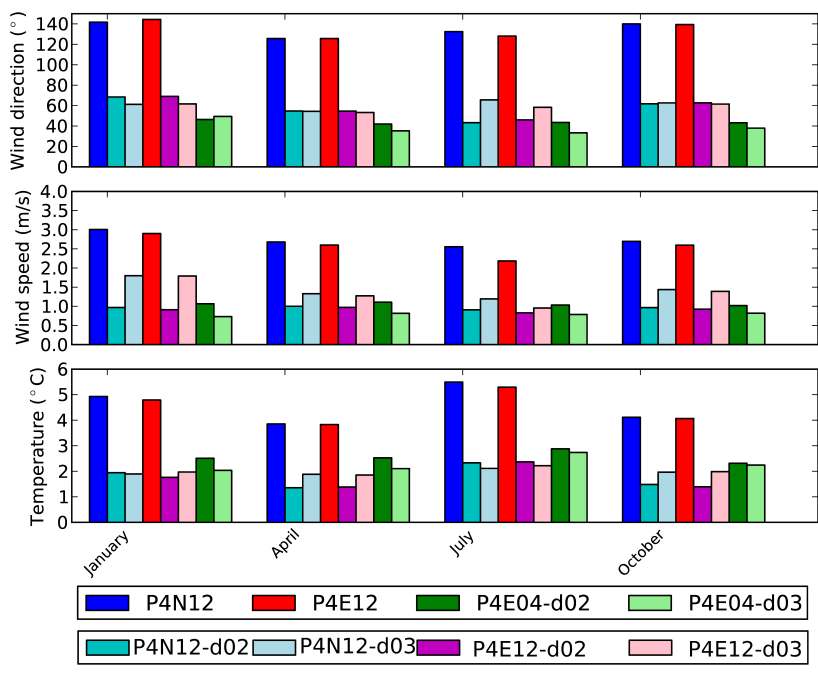

Fig. 4. Domain-wide RMSE of the bi-hourly difference between WRF simulated temperature, wind speed and wind direction and the METAR measured data for January, April, July and October 2009 for domains d01 (12 km resolution, California), d02 (4 km resolution, San Diego) and d03 (4 km resolution, San Francsico). The RMSE for the domains $\mathrm{d} 02$ and $\mathrm{d} 03$ using the $12 \mathrm{~km}$ resolution simulation are plotted in cyan and magenta, and in light blue and pink respectively.

in August suggest that these time periods may not be suitable to use in the emission inversion. At the other sites (not shown), as for SAN, the wind and temperature are similarly rather insensitive to the PBL scheme used.

In conclusion, for all sites in January, WRF is capable of reproducing the surface parameters properly without any large difference between the PBL schemes. In August, the wind direction during night is more challenging.

In addition to daily cycles at surface level, it is important to evaluate the vertically-resolved wind and temperature in WRF. We have plotted in Fig. 5 the monthly median vertical profile of temperature and wind speed for SAN, SFO and SMF. Data from LAX are very similar to SAN and are therefore not shown. As previously, there are no large differences between the schemes. Moreover, in terms of temperature, they perform remarkably well at all the sites. In the case of the wind speed, while the surface wind speed is generally in good agreement, the vertical profiles present more discrepancies, especially in August. In January, the disagreement comes mostly from the low altitude levels with modeled winds generally being too high. In particular at SMF, WRF seems to constantly simulate a higher wind speed near the surface. In August, on the contrary, the modeled winds are slower than observed, especially at the high altitude levels. Finally, we observe a $2 \mathrm{~m} \mathrm{~s}^{-1}$ underestimation of the whole mean vertical profile in August at SFO.

Overall, the wind and temperature from all PBL schemes do not show large differences between each other, which shows that wind and temperature profiles are rather insensitive to which PBL scheme is used. Moreover, compared to surface observations and vertical profiles, the schemes allow the observations to be closely reproduced in most cases. However, some discrepancies in the surface level wind direction in August at San Diego and in January at San Francisco, as well as an underestimation of the vertical profile of the wind speed $\left(2 \mathrm{~ms}^{-1}\right)$ and an overestimation of the surface and vertical profile of the temperature $\left(5^{\circ} \mathrm{C}\right)$ in August at San Francisco, are evident. In the next sections, we focus on one PBL scheme and test different options for meteorological boundary conditions and nesting. The chosen scheme is the MYNN2 (P4), which has been described as performing well for coastal regions (J. Dudhia, personal communication, 2011).

\subsection{Simulations with two different meteorological datasets - monthly averaged and synoptic data comparison}

Here, we have tested two different meteorological datasets for initial and lateral boundary conditions. The first, NAM, provides data at the same resolution as our coarse domain $(12 \mathrm{~km})$ while the second, ERA-interim, is of lower resolution but greater accuracy. We have simulated the whole year 2009 with both meteorological datasets. Using all the available METAR station data averaged in two hour bins, we have computed the domain wide root-mean-squared error (RMSE) of the difference between the WRF results and the observed data for temperature, wind speed and wind direction for January, April, July and October (Fig. 4). The results for the two meteorological datasets are plotted in red and blue and the RMSE is calculated over the whole $12 \mathrm{~km}$ resolution domain. The wind direction is the parameter that presents more discrepancies with the observations with about 120 to $140^{\circ}$ difference for both simulations. Except in January, P4E12 results in lower errors. For the wind speed and the temperature, the RMSE are much smaller, around 2.5 to $3 \mathrm{~m} \mathrm{~s}^{-1}$ for the wind speed and 4 to $6^{\circ} \mathrm{C}$ for the temperature. For all months, P4E12 yields a smaller RMSE.

The average diurnal cycles of wind direction, wind speed and temperature are presented in Fig. 6, For January, April, July and October 2009 at SAN and SFO where the simulation using NAM (P4N12b) is plotted in blue crosses and the ERAinterim simulation (P4E12) is plotted in red dots. Both generally follow the observed pattern at all sites and for all months. However, P4E12 performs better than P4N12b in several ways especially for the wind direction. At San Francisco, the wind speeds are overestimated by both datasets for all months, though P4E12 is closer to the observations. The same phenomenon is found at Los Angeles in July (not shown). Moreover, at SAN, in July, the wind direction is modeled better by P4E12 even though the sea breeze is still too strong compared to the observations, while for the temperature cycles, P4N12b performs better than P4E12. 

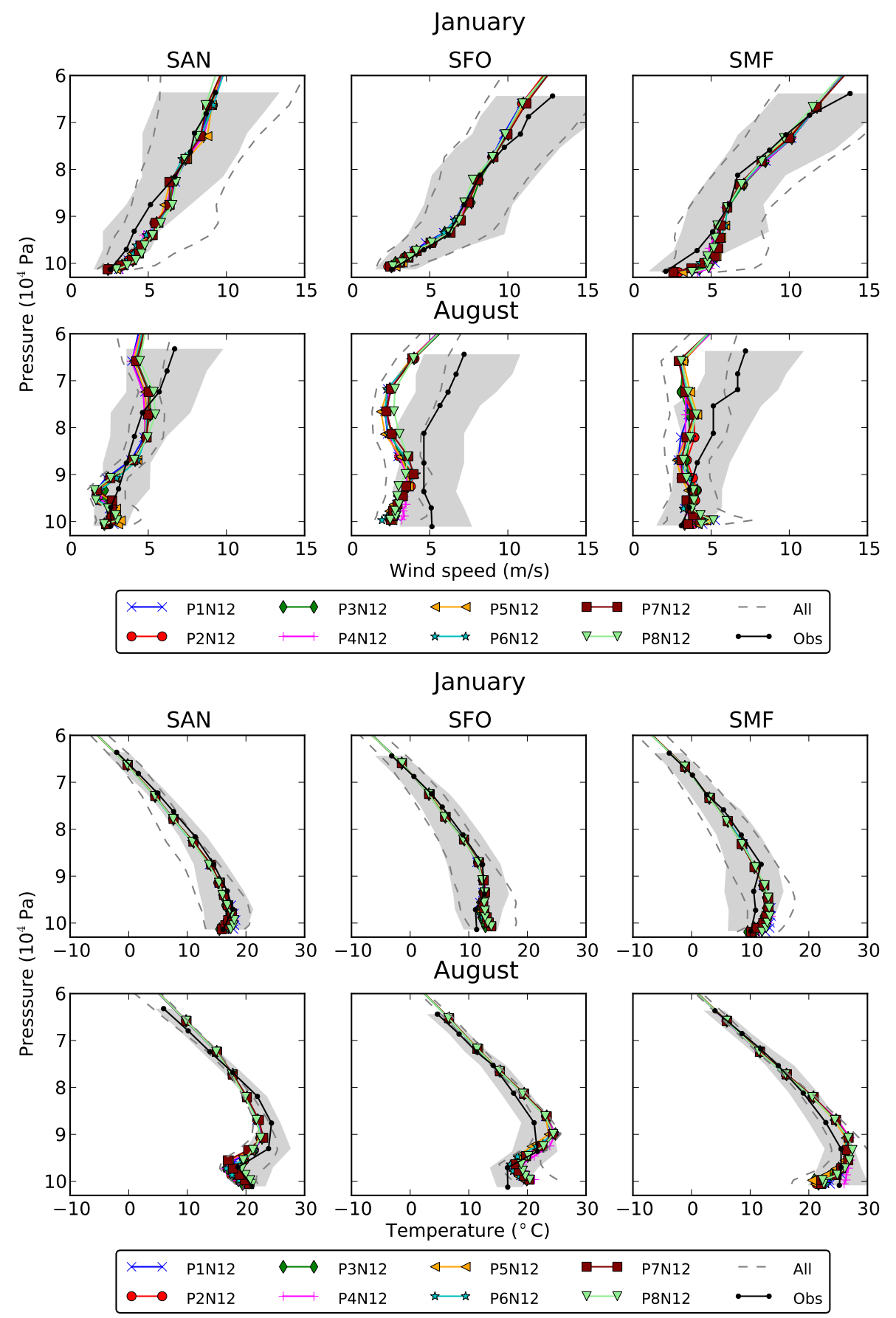

Fig. 5. Vertical profiles of the monthly median wind speed and temperature averaged over January and August 2009 for the eight PBL schemes and the observations at three of the airports (SAN, SFO and SMF). The profiles go from ground to around $4 \mathrm{~km}$. The grey envelope represents the upper and lower quartiles of the observations. The grey dotted line shows the upper and lower quartiles for all the simulations together.

In Fig. 7, the monthly average vertical profiles of wind speed and temperature are plotted for SAN, SFO and SMF, in a similar way to Figure 5. The same color code as above is used. For the wind speed, we observe good agreement in the high levels for both P4E12 and P4N12b at all sites, except in July, when the wind speed is either strongly overestimated (at SAN) or strongly underestimated (at SFO and SMF) by P4N12b. P4E12 clearly performs better in the high levels than P4N12b. At the lower levels, the simulated wind speeds show higher values at all sites and in all months for both 

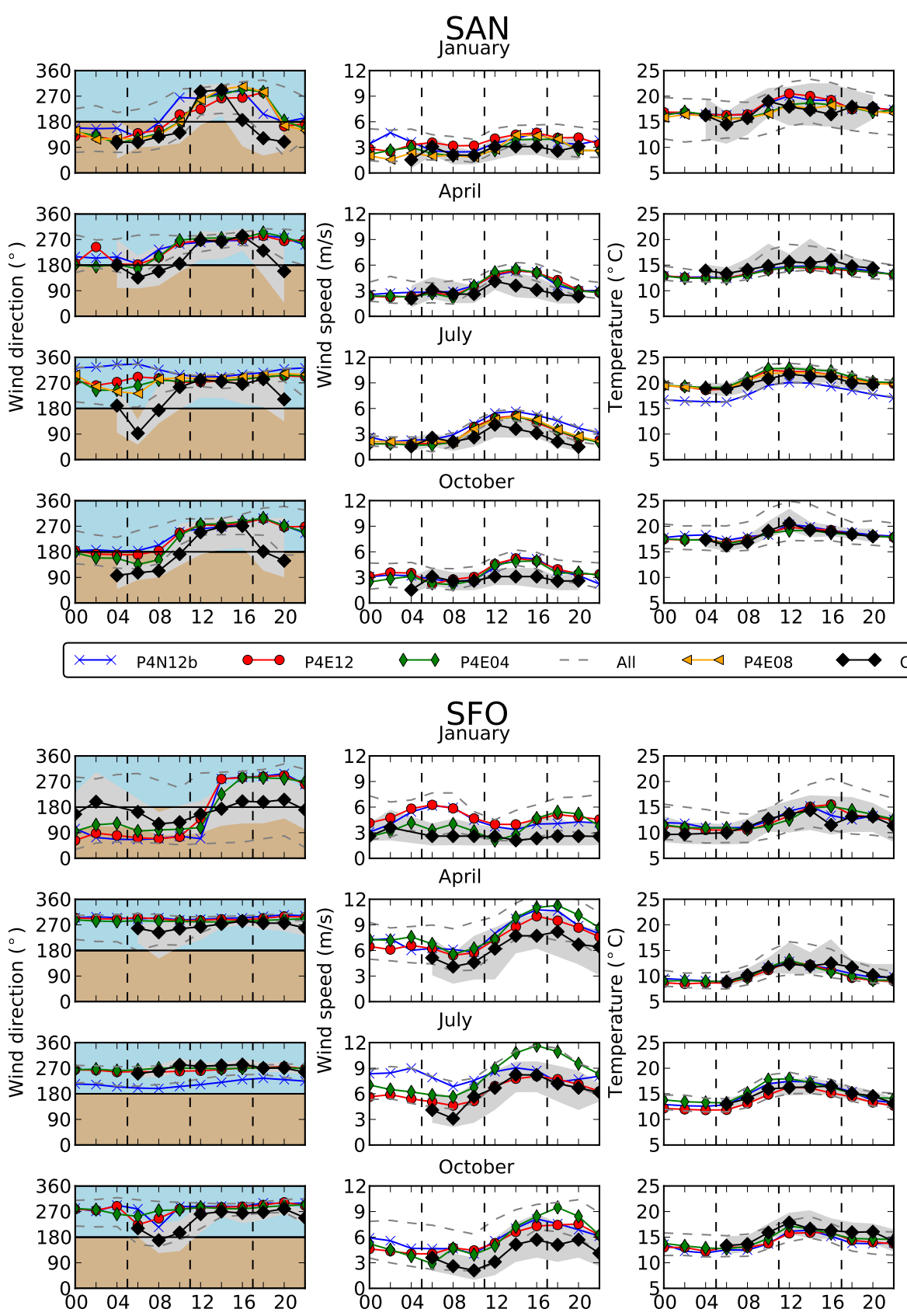

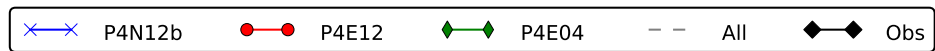

Fig. 6. Diurnal cycle of the surface wind direction, wind speed and temperature at SAN and SFO for January, April, July and October 2009 (local time) in simulations varying the boundary conditions and nesting options using median. For the wind direction, the blue area represents wind from the west while the tan area is for winds from the east. The grey envelope represents the upper and lower quartiles of the observations. The grey dotted line shows the upper and lower quartiles for all the simulations together.

simulations, which is not what is observed. However, P4E12 usually simulates a smaller difference than P4N12b. For the temperature profiles, there are no large differences between observations and simulations. We observe only a slight overestimation of about $1{ }^{\circ} \mathrm{C}$ for the low levels in July and October at all sites and in January at Sacramento for P4E12, while
P4N12b underestimates the temperature in July at all sites in the higher levels, and at SAN and LAX at the lower levels, but overestimates the lower level temperatures at SFO and SMF.

In conclusion, using ERA-interim as initial and lateral boundary conditions improves the simulation in comparison 

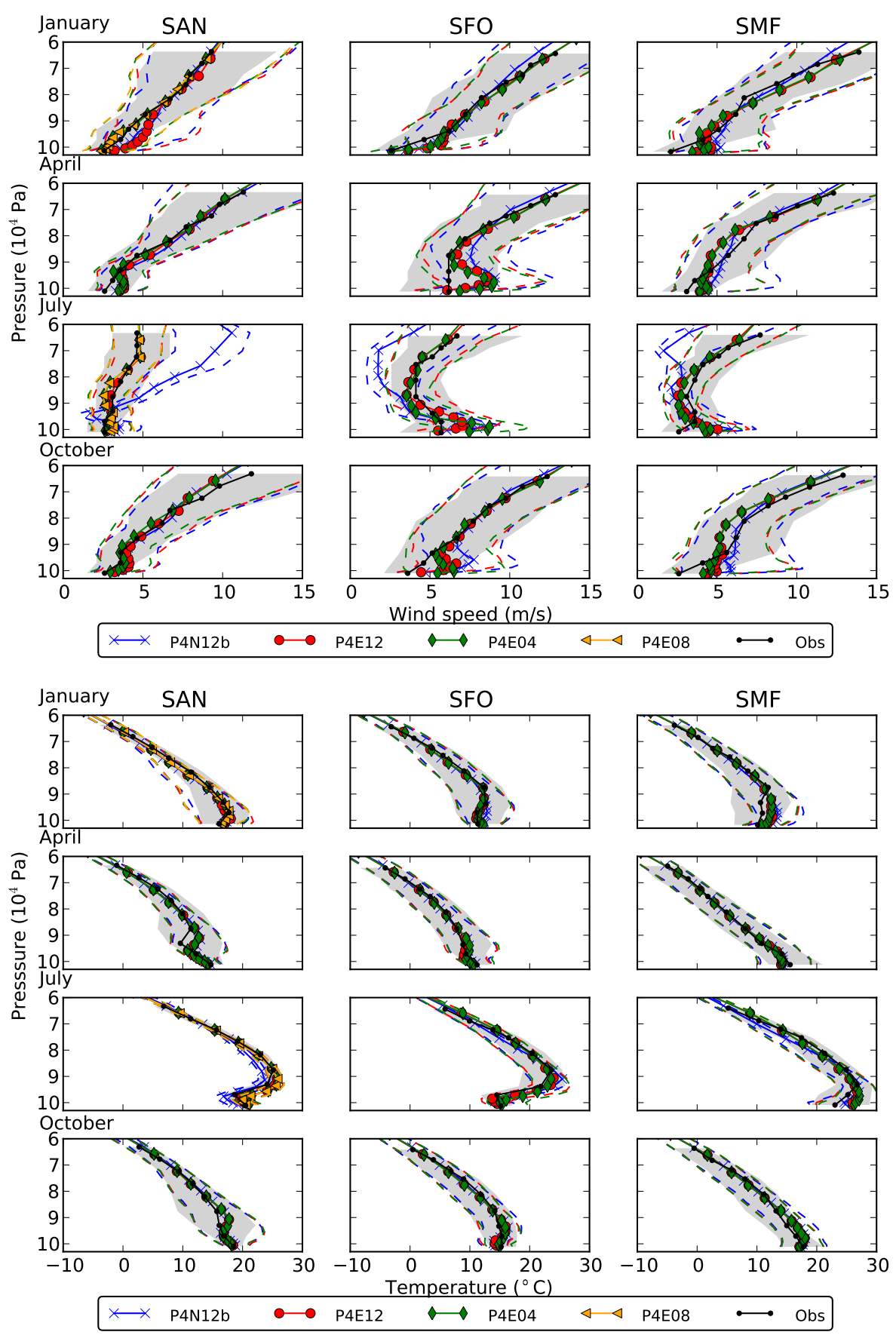

Fig. 7. Vertical profile of the monthly median wind speed and temperature at SAN, SFO and SMF for January, April, July and October 2009 in simulations varying the boundary conditions and nesting options. The grey envelope represents the upper and lower quartiles of the observations. The dotted lines show the upper and lower quartiles for each simulation. The profiles go from ground to around $4 \mathrm{~km}$.

to using NAM. We show that in our case, using reanalyzed initial and lateral boundary conditions tends to improve the simulations more than using initial and lateral boundary conditions with a higher spatial resolution. Moreover, the difference between the two is larger than the differences between the various PBL schemes. It seems that, here, initial and lateral boundary conditions have a larger influence on the simulated wind and temperature than the choice of the PBL scheme. 


\subsection{Simulations with nesting - monthly averaged and synoptic data comparison}

As previously, we have calculated the RMSE for the $4 \mathrm{~km}$ resolution domains (Fig. 4). To be comparable, we have also calculated the RMSE on the $12 \mathrm{~km}$ resolution grid using only the stations in the $4 \mathrm{~km}$ resolution domains. They are plotted in cyan and magenta for $\mathrm{d} 02$ and in light blue and pink for d03. For the smaller coastal domains, the RMSE is smaller for all parameters and simulations, which seems to indicate that the higher discrepancies are located inland. The average RMSE reaches 40 to $60^{\circ}$ for the wind direction, 1 to $2 \mathrm{~m} \mathrm{~s}^{-1}$ for the wind speed and $2{ }^{\circ} \mathrm{C}$ for the temperatures. As for the larger domain, P4E12 usually performs slightly better than $\mathrm{P} 4 \mathrm{~N} 12$ on the smaller domains. The $4 \mathrm{~km}$ resolution simulation also yields smaller RMSE than the $12 \mathrm{~km}$ resolution simulations for the wind direction. However, for the wind speed and the temperature, the RMSE for P8E12 is slightly higher than for P4E12 but the differences are not significant.

In Fig. 6, the diurnal cycles of surface wind speed, direction and temperature are also plotted for simulations using nests of $4 \mathrm{~km}$ resolution (green diamonds) and $0.8 \mathrm{~km}$ resolution, (gold triangles, only for January and July at SAN). At SAN, two nests are embedded, one at $4 \mathrm{~km}$ resolution (P4E04) and a second, at $0.8 \mathrm{~km}$ resolution (P4E08). First, comparison of the $4 \mathrm{~km}$ and $0.8 \mathrm{~km}$ nests at SAN shows that no significant difference comes from using this highest resolution nest. The Pearson's correlation coefficients between the observations and the nested runs are the same ( 0.9 for the wind direction, 0.4 for the wind speed and 0.9 for the temperature), as are the mean differences between observed and simulated temperature and wind. The mean differences for the wind direction are, however, larger in P4E08. It seems then that at SAN using a $0.8 \mathrm{~km}$ resolution nest does not provide better results than the $4 \mathrm{~km}$ resolution nest, while using much more computational time (about 4 times the cost).

We now focus on the comparison between the $12 \mathrm{~km}$ and $4 \mathrm{~km}$ resolution simulations (P4E12 and P4E04) in Figs. 6 and 7. If we compare the nested winds to the observations, the results are usually better than for the coarse winds, especially for wind direction and temperature. Generally, the land-sea breeze is better represented by the nested simulation. However, in July at San Diego, or in April at SFO, the nested wind direction is nearly identical to the coarse wind direction, showing no improvement. In terms of wind speed at SAN, there is also little difference. However, at Los Angeles, the nested wind speeds in the afternoon are closer to the observations than the coarse wind speeds (not shown). At SFO, we observe the opposite phenomenon, with the nested wind speed being overestimated compared to the coarse wind speed. Finally, at Sacramento, the wind speed is generally overestimated (by $\approx 2 \mathrm{~ms}^{-1}$ ) for all simulations, except in July, when the nested wind speed is closer to the observations than the coarse wind speed. In term of temperatures, there are no large differences between the coarse and nested tem- peratures, except at San Francisco in July where the nested temperatures are overestimated by $2^{\circ} \mathrm{C}$. At all coastal sites, there is a slight overestimation of the temperature, which is most pronounced in January at SAN and SFO.

In Fig. 7, the vertical profiles, as for the surface observations, present no significant difference between the $4 \mathrm{~km}$ and the $0.8 \mathrm{~km}$ resolution simulation. The $4 \mathrm{~km}$ nested temperatures correspond closely to the coarser modeled temperatures. In general, as for the surface temperature, there is a slight overestimation of the profile temperatures especially in July for all simulations. For the wind speed profiles, at San Diego in January and October, the lower levels are better modeled by the nested simulation than by the coarse simulation. At SMF, the nested simulation helps reduce the modeled higher wind speed but still underestimates the wind speed at mid-level in July. The same phenomenon is observed at San Francisco. For the other time periods and sites, there is little difference between the $4 \mathrm{~km}$ and the $12 \mathrm{~km}$ simulations.

In general, the nested simulation brings a better agreement than the coarse simulation, especially at San Diego. However, adding nests can also increase the model bias, for example in the mid-level winds at San Francisco or Sacramento.

\subsection{Effect on the modeling of an inert tracer}

As our ultimate goal is to invert emissions of HFC-134a using WRF simulations and atmospheric HFC-134a measurements, we also examine the modeled HFC-134a concentrations compared to observed HFC-134a concentrations. We use here a simulation with at $12 \mathrm{~km}$ resolution without nesting, ERA-interim as initial and boundary conditions, and MYNN2 as PBL scheme. We also add a simulation that includes the chemistry package WRF/CHEM (Grell et al., 2005) to compute tracer transport (P4E12c) while the other simulation uses the WRF tracer option to compute tracer transport. There are errors in tracer concentration in WRF, as opposed to WRF/CHEM, that result from inaccurate treatment of tracer transport. The tracer option in WRF does not explicitly solve the full advection-diffusion equation for tracer transport (see WRF description report: www.mmm. ucar.edu/wrf/users/docs/arw_v3.pdf) but rather simply transports particles by integrating the wind fields computed during each time step. This tracer option is not linked to any physics sub-routines, which means that tracers released at the surface are not appropriately affected by PBL processes. Within the chemistry module included in WRF/CHEM, vertical mixing of tracers is done separately from the physics package but uses coefficients provided by the physics package. This requires that the PBL scheme is a local closure scheme, such as the MYNN2 scheme that we are using. In addition, some specific physical and dynamics options are recommended to be used with the WRF/CHEM module (WRF/CHEM user's manual ruc.noaa.gov/wrf/WG11/ Users_guide.pdf), which we have implemented. In particular, the cumulus radiation feedback option was activated to 
avoid surface and skin temperatures that are too high. Advection for the moist, chemical, scalar and tracer variables was changed from positive-definite to monotonic. This corrects the tendency of WRF to overshoot and produce unrealistically low local values (Peckam et al., 2011). To avoid negative values for variables such as precipitation, the option "mp_zero_out" was activated. As it also applies to the tracer, we chose a threshold value of $1 \times 10^{-16}$.

The simulated surface temperature and wind shows only slight differences between WRF and WRF/CHEM (not shown) which are likely related to the physical and dynamics options we adjusted for WRF/CHEM. As for the surface data, no substantial differences exist between the simulations with or without chemistry options for the monthly averaged vertical profiles of the wind speed and temperature (not shown). We are therefore confident that our conclusions concerning the validation of the transport in the model are still valid with the WRF/CHEM setup.

In the model, the tracer is initialized with zero values. To compare with the observations, we are plotting the residuals or excess of the observations with the background removed. The residuals are in ppt, that is to say, dry air mole fraction $\times 10^{-12}$. The two simulations P4E12 and P4E12c follow the same general pattern with lower values in the afternoon and higher values at night and in the morning (Fig. 8). This pattern corresponds to the diurnal cycle of the PBL height over land (Fig. 2) as well as the effect of the afternoon sea breeze, which tends to bring clean well-mixed air masses to the measurement station at SIO. A large difference between the P4E12c simulation using WRF/CHEM and the other simulation is apparent: P4E12c simulates much lower residuals that correspond more closely to the observed residuals (Fig. 8). However, P4E12c residuals are still approximately two times too high in the time series. For the diurnal cycle, however, the median values are closer to the observed values but the quartile position shows that the distribution is skewed with some high outliers, which is consistent with the differences seen in the time series. This shows that we cannot just use a scaling factor to estimate the emissions. The observed residuals are the results of a spatial distribution of emissions which needs to be corrected or of errors in the vertical mixing, which we were not able to assess. The high simulated nighttime values result mainly from the San Diego County basin while the low values are simulated in the afternoon, when the air masses are well-mixed and represent larger source regions (not shown). Qualitatively, it seems that the estimated San Diego County emissions are too large while some of the neighboring basins could be underestimated. Top-down estimates of emissions will benefit from a more complex inversion, as well as using the second station at Trinidad Head.
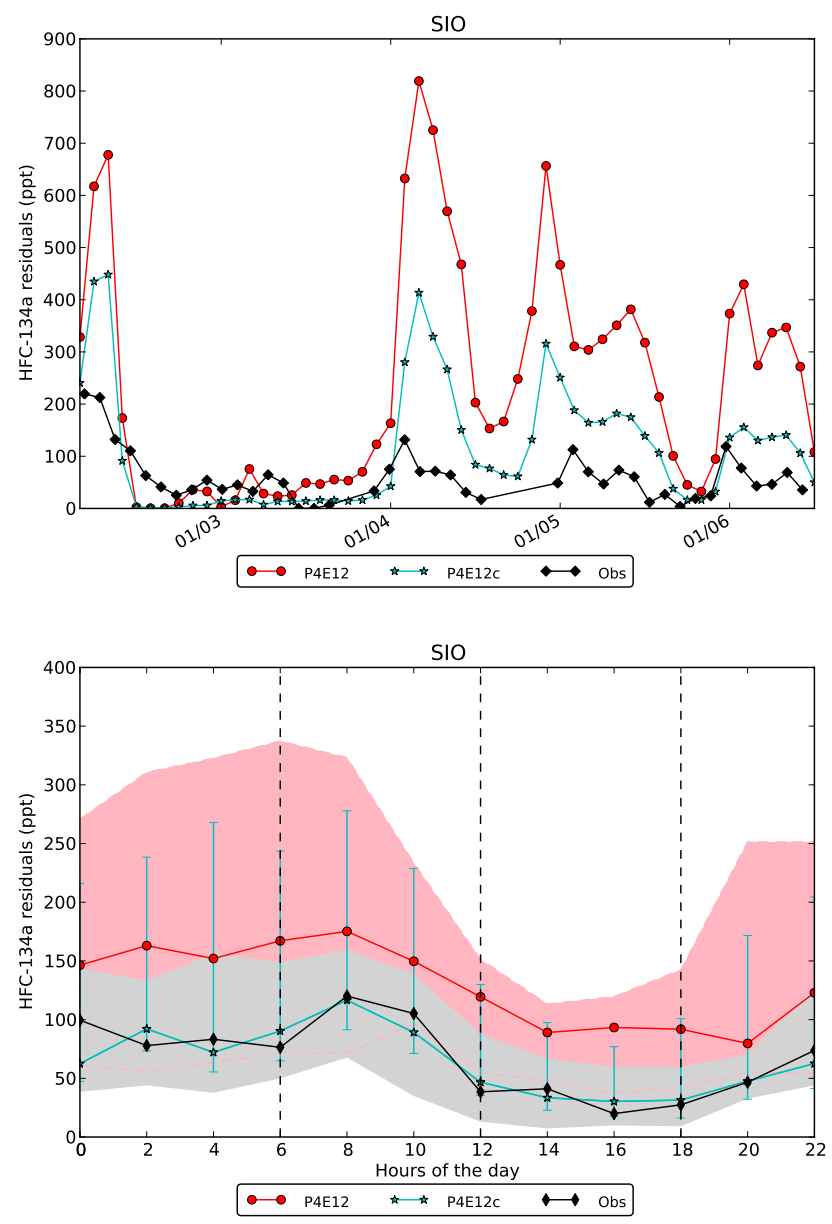

Fig. 8. HFC-134a simulated and observed residuals (mixing ratios minus background) during four days in January 2009 and diurnal cycle for the whole month using median at SIO. The grey envelope represents the upper and lower quartiles of the observations around the median. The pink envelope represents the upper and lower quartiles of the P4E12 simulation without chemistry. The upper and lower quartiles for P4E12c are indicated by vertical bars.

\subsection{Simulation of a Santa Ana event in December 2009 - Synoptic data comparison}

Santa Ana events are a large-scale weather pattern encountered in Southern California, generally between October and March. They are characterized by a positive pressure gradient from the Great Basin to the coast, which leads to strong winds that transport dry and warm air masses offshore (Raphael, 2003; Hughes and Hall, 2010; Hughes et al., 2011). After such an event, these air masses can also return onshore. In the case of San Diego, this recirculation brings air from the Los Angeles area as well as from the San Francisco Bay area. The air masses therefore contain information at a regional scale that can help us constrain large parts of California.

The Climate Research Division at SIO calculates a Santa Ana index using the pressure gradient between the 
Table 3. Measured and modeled pressure (HPa) at San Diego Airport and Ely/Yelland field station

\begin{tabular}{ccccc}
\hline Date & $\begin{array}{c}\text { Measured at } \\
\text { San Diego }\end{array}$ & $\begin{array}{c}\text { Measured at } \\
\text { Ely/Yelland }\end{array}$ & $\begin{array}{c}\text { Modeled at } \\
\text { San Diego }\end{array}$ & $\begin{array}{c}\text { Modeled at } \\
\text { Elly/Yelland }\end{array}$ \\
\hline 19 December 12 p.m. & 1014 & 1031 & 1016 & 1022 \\
20 December 20 p.m. & 1018 & 1022 & 1018 & 1018 \\
\hline
\end{tabular}
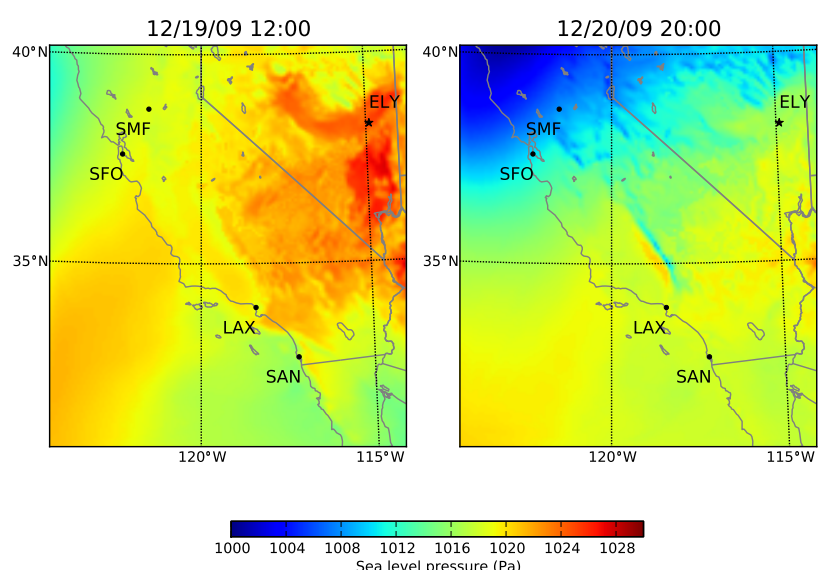

Sea level pressure $(\mathrm{Pa})$
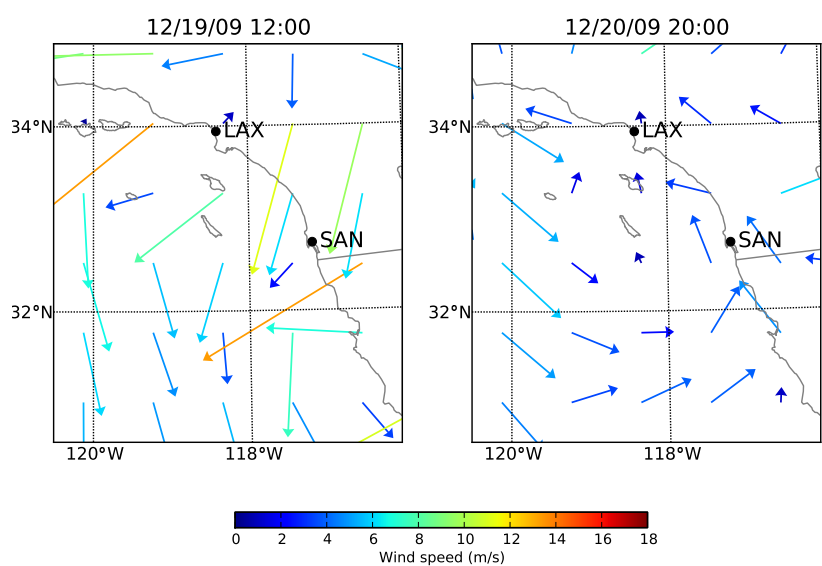

Fig. 9. Sea-level pressure maps above California for 19 and 20 December 2009 at noon (local time) for the P4E12c simulation. Wind pattern above Los Angeles and San Diego; the direction is indicated through arrows while the speed is plotted in a color scale.

Ely/Yelland field station in Nevada $\left(38.3^{\circ} \mathrm{N}, 114.9^{\circ} \mathrm{W}\right)$ and the San Diego airport. Data are available publicly for periods beginning in December 2009 (http://meteora.ucsd.edu/ weather/other/old_SAIndex/). For this month, several events were observed. We focus on the events from 17 to 20 December. In Fig. 9, we plot the simulated (P4E12c) surface wind direction and speed, as well as the sea level pressure, on December 19 at 12 p.m. (local time) during the Santa Ana event, and 20 December at 8 p.m. (local time) at the end of the event. As expected, on December 19, we observe a strong pressure gradient from the northeast to the coast. The simu- lated pressures in the model grid cell containing Ely and San Diego airport are 1016 and $1022 \mathrm{hPa}$ while the measurements indicate 1014 and $1031 \mathrm{hPa}$ respectively (see Table 3). This situation leads to simulated strong offshore winds in Southern California. On 20 December, in the evening, the situation has changed. The pressure gradient is weaker. The pressures at San Diego and Ely were measured at 1018 and $1022 \mathrm{hPa}$, while the model computes 1018 and $1018 \mathrm{hPa}$ respectively. The simulated wind speeds are two to five times slower, and the air masses circle around the ocean and come back onshore along San Diego coast. This shows that our configuration of WRF is able to reproduce the large-scale meteorological conditions of a Santa Ana event.

In Fig. 10, we examine whether Santa Ana events have strong local signatures in the simulated and observed wind direction, wind speed, temperature at SAN and LAX, and HFC-134a residuals at SIO from 17 to 23 December 2009. The Santa Ana events are highlighted by the grey shaded areas. We observe a general good agreement of the wind direction, wind speed and temperature at SAN and LAX between the observations and the simulation. In the case of LAX, using the grid cell which contains the station gave poor results in term of temperatures, with no daily variations at all. However, using the east next gridcell, more inland, gives a near perfect agreement. As the station is not perfectly in the center of the gridcell and as this gridcell is mainly oceanic, we have chosen to plot the temperauture from the next eastern gridcell. For the four events, we observe the same pattern in the wind direction with winds shifting sharply from the west to the east. At the end of the events, at SAN, the wind direction is mainly north, north-west bringing air from Los Angeles to San Diego. At Los Angeles, the wind direction still shifts but with less regularity than during the Santa Ana events. For the wind speed and the temperatures, we observe a peak of these parameters during each event. After the Santa Anas, the temperatures drop while the wind speed slowly rises.

In terms of HFC-134a residuals at SIO (La Jolla), observed and simulated residuals are of the same order of magnitude even if large residuals tend to be too large in the simulation. In Fig. 10, the afternoon residual values (between 12 p.m. and 6 p.m.) are highlighted in cyan and black for the simulation and observation respectively while the whole data sets are in powder blue and grey. During the Santa Ana events, the mixing ratios tend to decrease. This could be explained by the fact that during this period, the winds are coming from the west bringing clean oceamic air. At the end of each 

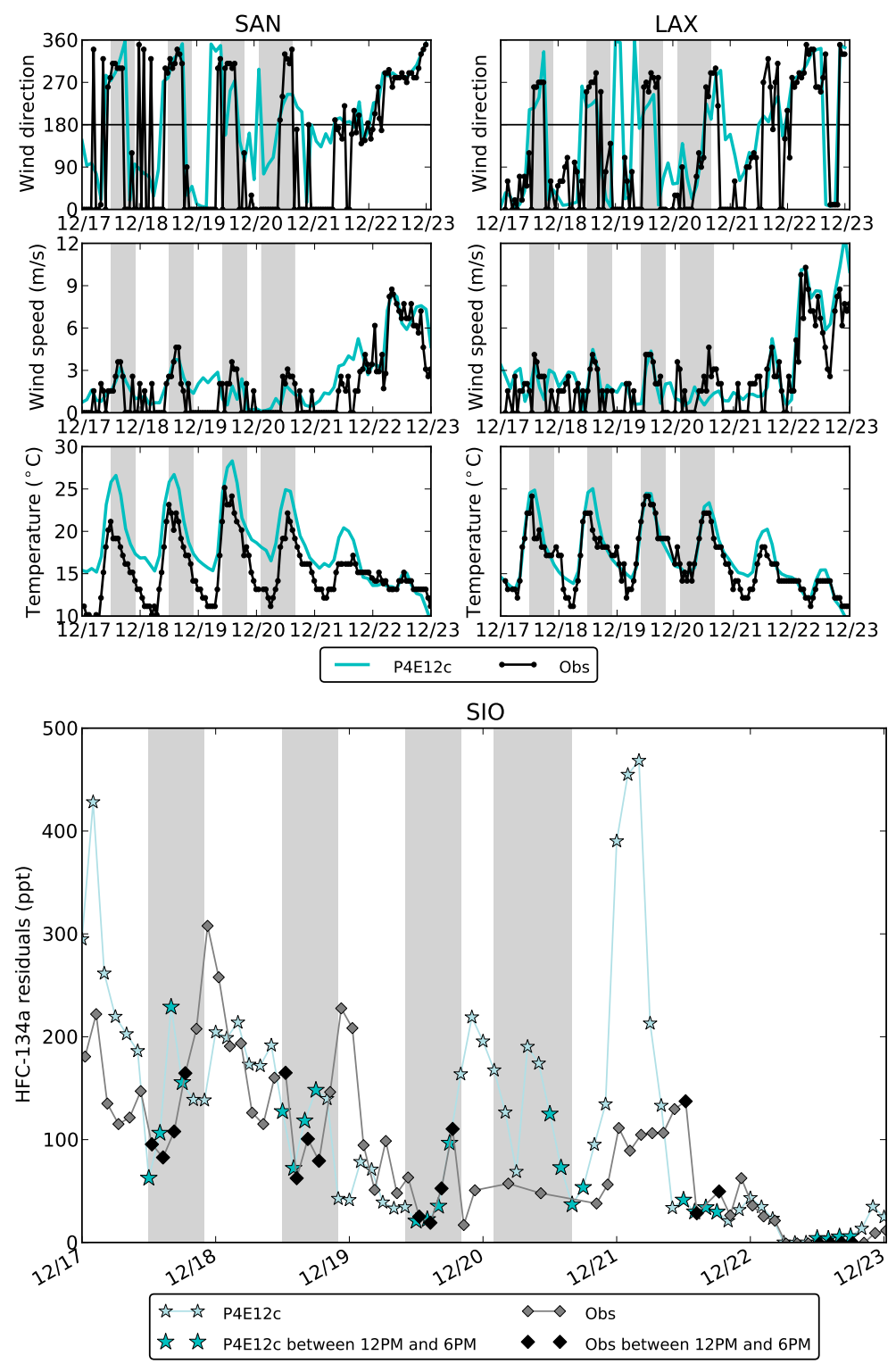

Fig. 10. Wind direction, wind speed, temperature and HFC-134a observed and simulated (P4E12c) residuals between 17 and 25 December 2009. The Santa Ana events are shown with grey bars.

event, when the wind shifts to east, we observe an increase of the concentrations. On 21 December, the wind direction in the simulation is from the north, bringing air masses from Los Angeles and the other coastal regions, and the simulated residual peaks at $480 \mathrm{ppt}$. In the observations, the wind direction is first south then north and therefore the resulting mixing ratio is lower, but still higher than the day before. Finally, on 22 December, the wind blows strongly from the west, bringing clean air masses, and both simulated and observed residuals are near the background values. From these short series of Santa Ana events, we show that the model is able to reproduce the meteorology as well as the concentra- tion patterns. The study of more events is needed but this shows promising results.

\section{Conclusions}

We have evaluated the transport in the WRF model by comparing wind direction, wind speed and temperature at four airports in California, with the goals of assessing biases in modeled winds and temperatures and seeing how changing the PBL schemes, the initial and lateral boundary condition datasets, and the model resolution could reduce these biases. We have tested eight available planetary boundary layer schemes, two initial and lateral boundary condition datasets, 
and nesting options. No major differences in the temperature and winds arise from using different PBL schemes. Better agreement with observations is generally obtained using ERA-interim reanalysis and GODAE SST instead of NAM and RTG_SST as initial and lateral boundary forcings. We also show that increasing the resolution helps to improve the match between observed and simulated wind and temperature, especially in topographically challenging areas such as the California coast. But no further improvement was found at San Diego for $0.8 \mathrm{~km}$ resolution, as compared to $4 \mathrm{~km}$ resolution.

We have also looked at the effects of these different approaches on simulations of the inert tracer HFC-134a. We show that tracer transport calculated using the WRF/CHEM model is improved, compared to tracer transport computed with the tracer option in the WRF model. Comparing time series and diurnal cycles, it appears that inversion is needed to be able to the correct emission pattern as the spatial distribution clearly has a large influence on the observations. Finally, we have shown that our model reproduces events like Santa Anas, which is an important pathway for the transport of emissions from large part of California, and especially the Los Angeles area, to our observation site in La Jolla.

Acknowledgements. Thanks to Wayne Angevine at NOAA, Anders Nottrott at UCSD, and the WRF support team for their advice on WRF configuration. We gratefully thank the WRF and Livermore Computing support teams. Super-computer resources were provided by Livermore Computing at the Lawrence Livermore National Laboratory. This work is funded by a grant from the US National Institute of Science and Technology (NIST). Part of this work was performed under the auspices of the US Department of Energy by Lawrence Livermore National Laboratory under Contract DE-AC52-07NA27344.

Edited by: M. Heimann

\section{References}

Angevine, W. M., Jiang, H., and Mauritsen, T.: Performance of an Eddy Diffusivity-Mass Flux Scheme for Shallow Cumulus Boundary Layers, Mon. Weather Rev., 138, 2895-2912, doi:10.1175/2010MWR3142.1, 2010.

Angevine, W. M., Eddington, L., Durkee, K., Fairall, C., Bianco, L., and Brioude, J.: Meteorological Model Evaluation for CalNex 2010, Mon. Weather Rev., 140, 3885-3906, doi:10.1175/MWRD-12-00042.1, 2012.

Bougeault, P. and Lacarrère, P.: Parameterization of orographic induced turbulence in a mesobeta scale model, Mon. Weather Rev., 117, 1872-1890, 1989.

Bretherton, C. S., Uttal, T., Fairall, C. W., Yuter, S. E., Weller, R. A., Baumgardner, D., Comstock, K., Wood, R., and Raga, G. B.: The Epic 2001 Stratocumulus Study, B. Am Meteorol. Soc., 85, 967977, doi:10.1175/BAMS-85-7-967, 2004.

Chen, F. and Dudhia, J.: Coupling an Advanced Land Surface Hydrology Model with the Penn State NCAR MM5 Modeling
System. Part 1: Model Implementation and Sensitivity, Mon. Weather Rev., 129, 569-585, 2001.

Fast, J. D., Gustafson, W. I., Berg, L. K., Shaw, W. J., Pekour, M., Shrivastava, M., Barnard, J. C., Ferrare, R. A., Hostetler, C. A., Hair, J. A., Erickson, M., Jobson, B. T., Flowers, B., Dubey, M. K., Springston, S., Pierce, R. B., Dolislager, L., Pederson, J., and Zaveri, R. A.: Transport and mixing patterns over Central California during the Carbonaceous Aerosol and Radiative Effects Study (CARES), Atmos. Chem. Phys. Discuss., 11, 2994930008, doi:10.5194/acpd-11-29949-2011, 2011.

Gibbs, J. A., Fedorovich, E., and van Eijk, A. M. J.: Evaluating Weather Research and Forecasting (WRF) Model Predictions of Turbulent Flow Parameters in a Dry Convective Boundary Layer, J. Appl. Meteorol. Climatol., 50, 2429-2444, doi:10.1175/2011JAMC2661.1, 2011.

Grell, G. A. and Dévényi, D.: A generalized approach to parameterizing convection combining ensemble and data assimilation techniques, Geophys. Res. Lett., 29, 4 pp., doi:10.1029/2002GL015311, 2002.

Grell, G. A., Peckham, S. E., Schmitz, R., McKeen, S. A., Frost, G., Skamarock, W. C., and Eder, B.: Fully coupled "online" chemistry within the WRF model, Atmospheric Environment, 39, 6957-6975, doi:10.1016/j.atmosenv.2005.04.027, 2005.

Holt, T. and Raman, S.: A review and comparative evaluation of multilevel boundary layer parameterizations for first-order and turbulent kinetic energy closure schemes, Rev. Geophys., 26, 761-780, doi:10.1029/RG026i004p00761, 1988.

Hong, S., Dudhia, J., and Chen, S.: A Revised Approach to Ice Microphysical Processes for the Bulk Parameterization of Clouds and Precipitation, Mon. Weather Rev., 132, 103-120, doi:10.1175/1520-0493(2004)132<0103:ARATIM>2.0.CO;2, 2004.

Hong, S., Noh, Y., and Dudhia, J.: A New Vertical Diffusion Package with an Explicit Treatment of Entrainment Processes, Mon Weather Rev., 134, 2318-2341, doi:10.1175/MWR3199.1, 2006.

Hu, X., Nielsen-Gammon, J. W., and Zhang, F.: Evaluation of Three Planetary Boundary Layer Schemes in the WRF Model, J. Appl. Meteorol. Climatol., 49, 1831-1844, doi:10.1175/2010JAMC2432.1, 2010.

Hughes, M. and Hall, A.: Local and synoptic mechanisms causing Southern California's Santa Ana winds, Clim. Dynam., 34, 847857, doi:10.1007/s00382-009-0650-4, 2010.

Hughes, M., Hall, A., and Kim, J.: Human-induced changes in wind, temperature and relative humidity during Santa Ana events, Clim. Change, 109, 119-132, doi:10.1007/s10584-011-0300-9, 2011.

IPCC 2007: Summary for Policymakers, in: Climate Change 2007: The Physical Science Basis. Contribution of Working Group I to the Fourth Assessment Report of the Intergovernmental Panel on Climate Change, edited by: Solomon, S., Qin, D., Manning, M., Chen, Z., Marquis, M., Averyt, K. B., Tignor, M., and Miller, H. L., Cambridge, UK and New York, NY, USA, Cambridge University Press, 2-9, 2007

Janjic, Z.: Nonsingular implementation of the Mellor Yamada level 2.5 scheme in the NCEP Meso model, NCEP Office Note 437, p. $60,2002$.

Miller, B. R., Weiss, R. F., Salameh, P. K., Tanhua, T., Greally, B. R., Mühle, J., and Simmonds, P. G.: Medusa: a sample preconcentration and GC/MS detector system for in situ measurements of 
atmospheric trace halocarbons, hydrocarbons, and sulfur compounds, Analyt. Chem., 80, 1536-1545, doi:10.1021/ac702084k, 2008.

Mlawer, E. J., Taubman, S. J., Brown, P. D., Iacono, M. J., and Clough, S. A.: Radiative transfer for inhomogeneous atmospheres: RRTM, a validated correlated-k model for the longwave, J. Geophys. Res., 102, 16663-16682, doi:10.1029/97JD00237, 1997.

Nakanishi, M. and Niino, H.: An Improved Mellor Yamada Level3 Model: Its Numerical Stability and Application to a Regional Prediction of Advection Fog, Bound.-Layer Meteorol., 119, 397407, 2006.

Nisbet, E. and Weiss, R.: Top-Down Versus Bottom-Up, Science, 328, 1241-1243, doi:10.1126/science.1189936, 2010.

Noh, Y., Cheon, W., Hong, S., and Raasch, S.: Improvement of the K-profile Model for the Planetary Boundary Layer based on Large Eddy Simulation Data, Bound.-Layer Meteorol., 107, 401-427, 2003.

Olivier, J. G. J., Bouwman, A. F., van der Maas, C. W. M., Berdowski, J. J. M., Veldt, C., Bloos, J. P. J., Visschedijk, A. J. H., Zandveld, P. Y. J., and Haverlag, J. L.: Description of EDGAR Version 2.0: A set of global emission inventories of greenhouse gases and ozone-depleting substances for all anthropogenic and most natural sources on a per country basis and on 1 degree x 1 degree grid, Rijksinstituut voor Volksgezondheid en Milieu RIVM, 1996.

Park, S. and Bretherton, C. S.: The University of Washington Shallow Convection and Moist Turbulence Schemes and Their Impact on Climate Simulations with the Community Atmosphere Model, J. Climate, 22, 3449-3469, doi:10.1175/2008JCLI2557.1, 2009.

Peckam, S. E., Grell, G. A., McKeen, S. A., Barth, M., Pfister, G., Wiedinmyer, C., Hewson, M., Freitas, S. R., Fast, J. D., Gustafson, W. I., Ghan, S. J., Zaveri, R., Easter, R. C., Barnard, J., Chapman, E., Schmitz, R., and Salzmann, M.: WRF/CHEM Version 3.4 User's Guide, available at: ruc.noaa.gov/wrf/WG11/ Users_guide.pdf (last access: 12 February 2013), 2011.
Pleim, J. E.: A Combined Local and Nonlocal Closure Model for the Atmospheric Boundary Layer. Part I: Model Description and Testing, J. Appl. Meteorol. Climatol., 46, 1383-1395, doi:10.1175/JAM2539.1, 2007a.

Pleim, J. E.: A Combined Local and Nonlocal Closure Model for the Atmospheric Boundary Layer. Part II: Application and Evaluation in a Mesoscale Meteorological Model, J. Appl. Meteorol. Climatol., 46, 1396-1409, doi:10.1175/JAM2534.1, 2007b.

Pleim, J. E. and Chang, J. S.: A non-local closure model for vertical mixing in the convective boundary layer, Atmos. Environ. A General Topics, 26, 965-981, doi:10.1016/0960-1686(92)90028J, 1992.

Prinn, R. G., Weiss, R. F., Fraser, P. J., Simmonds, P. G., Cunnold, D. M., Alyea, F. N., O'Doherty, S., Salameh, P., Miller, B. R., Huang, J., Wang, R. H. J., Hartley, D. E., Harth, C., Steele, L. P., Sturrock, G., Midgley, P. M., and McCulloch, A.: A history of chemically and radiatively important gases in air deduced from ALE/GAGE/AGAGE, J. Geophys. Res., 105, 1775117792, doi:10.1029/2000JD900141, 2000.

Raphael, M. N.: The Santa Ana Winds of California, Earth Interactions, 7, 1-13, doi:10.1175/10873562(2003)007<0001:TSAWOC>2.0.CO;2, 2003.

Shin, H. and Hong, S.: Intercomparison of Planetary BoundaryLayer Parametrizations in the WRF Model for a Single Day from CASES-99, Bound.-Layer Meteorol., 139, 261-281, doi:10.1007/s10546-010-9583-z, 2011.

Skamarock, W. C. and Klemp, J. B.: A time-split nonhydrostatic atmospheric model for weather research and forecasting applications, J. Comput. Phys., 227, 3465-3485, 2008.

Smagorinsky, J.: General Circulation Experiments with the Primitive Equations, Mon. Weather Rev., 91, 99-186, 1963.

Sukoriansky, S., Galperin, B., and Staroselsky, I.: A quasinormal scale elimination model of turbulent flows with stable stratification, Phys. Fluids, 17, 085107-085107-28, doi:10.1063/1.2009010, 2005. 